\title{
BOEKBESPREKING: SHOHAKU SHOW
}

De bruisende kunstwereld van Kyoto in de 18e eeuw is voor kunsthistorici een dankbaar onderwerp. Op veel gebieden in de kunst nam Kyoto toen een centrale plaats in. Kunstnijverheden als textiel, lakwerk en keramiek bloeiden en welgestelde bevolkingsgroepen als gerenommeerde handelaarsfamilies en de entourage van het Keizerlijk hof creëerden een vruchtbare voedingsbodem voor de kunsten. In de loop van de eeuw zag een aantal succesvolle, deels zeer vernieuwende kunstenaars er het daglicht. Voorbeelden uit de vroege jaren na 1700 zijn Ogata Kenzan (1663-1743) met zijn kleurrijke, levendig beschilderde keramiek, of zijn oudere broer Ogata Korin (1658-1716), die de

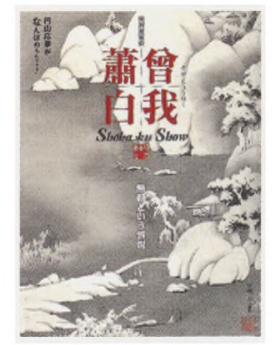
grondlegger was van de Rinpa-stroming in de schilderkunst. In de tweede helft van de eeuw volgde een groep schilders die de Japanse schilderkunst een ander gezicht zou geven. Een van de meest bekende is Maruyama Okyo (1733-1795). Hij gaf een nieuwe draai aan bestaande schilderstijlen en vestigde een nieuwe richting die het afbeelden naar de natuur centraal stelde. Zijn stroming had een groot aantal volgers, die deze leidraad op verschillende manieren interpreteerden. De populariteit van Okyo en zijn volgelingen viel niet bij iedereen in de smaak. Zijn in hun ogen te brave realisme druiste voor hen in tegen dat waar het in de inktschilderkunst om ging: de kracht van het penseel. Deze tegenhangers worden ook wel 'individualisten' genoemd en het Kyoto National Museum heeft hen tot het onderwerp gemaakt van tot nog toe twee tentoonstellingen, in wat hopelijk een lange reeks zal blijken te zijn. In 2000 waren de schilderingen van Ito Jakuchu (1716-1800) bijeengebracht voor de tentoonstelling Jakuchu!. Dit jaar was het de beurt aan de extravagante werken van de schilder Soga Shohaku (1730-1781), met de tentoonstelling Shohaku Show.

Shohaku was bepaald geen bewonderaar van het werk van Okyo en de zijnen. Het Japanse gedeelte van de catalogus refereert daar ook al gelijk aan op de omslag met de kreet 'Maruyama Okyo ga, nanbo no monja!' ('Maruyama Okyo, wat is die waard?!').' Shohaku stond bekend om zijn opstandig, arrogant gedrag en Okyo moest het ontgelden. Bekend is de uitspraak van Shohaku die in de catalogus dan ook op een van de eerste bladzijden staat: 'Wilt u een schildering, kom dan bij mij. Wenst u een plaatje, dan kunt u beter naar Maruyama'.

Het moet gezegd worden, schilderen kon Shohaku beslist. De afgebeelde werken in deze catalogus lopen over van de bravoure van zijn penseel, zoals het fabelachtige paar kamerschermen 'Onsterfelijken', dat hij op 35-jarige leeftijd maakte. Twee details daaruit staan op afbeeldingen 1 en 2 . Shohaku portretteerde op de schermen een bizarre wereld, bevolkt door figuren uit de Chinese mythologie die een merkwaardige blik in de ogen hebben. Nu zijn onsterfelijken ook rare wezens, die zich bezig houden met bovennatuurlijke praktijken, zoals hier het rijden op eendralak Shohakuiheeftmediezcè̀ne 03:52:07 AM 

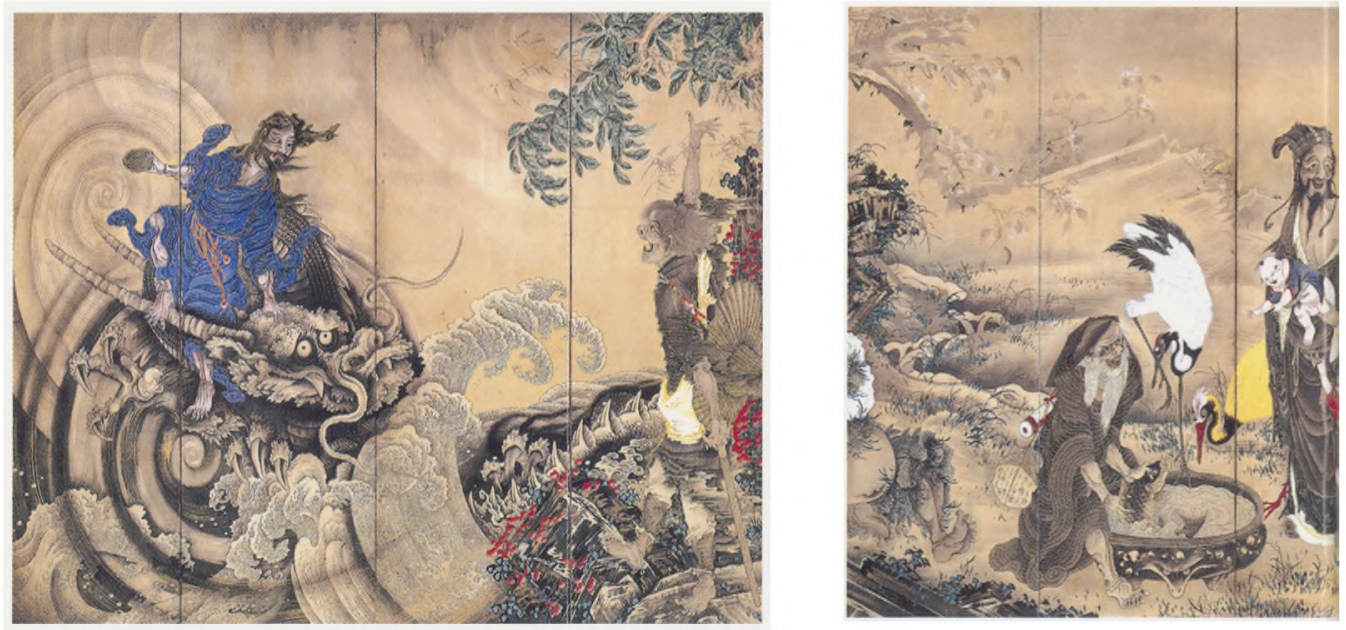

Afbeelding 1 (links) Onsterfelijken, detail, paar kamerschermen, inkt en kleur op papier, Japan, 1764, Agency for Cultural Affairs

Afbeelding 2

Onsterfelijken, detail, paar kamerschermen, inkt en kleur op papier, Japan, 1764, Agency for Cultural Affairs bijzonder raak getroffen, met krullende golven en cirkelende windvlagen die de figuur op de kust bijna uiteen doen waaien. De onsterfelijken op het andere detail zijn met hun grauwe gelaatskleur ook onmiddellijk te herkennen als bovenaardse wezens. Echter, waar een groep kinderen in de Chinese en Japanse mythologie steevast een blije blozende verzameling is, teken van voorspoed en lang leven, heeft Shohaku ook hen iets maniakaals in de ogen gelegd. Zoals de catalogus het uitdrukt: 'De afbeelding geeft de kijker het gevoel in een nachtmerrie te zijn'.

De vraag die vanzelfsprekend opkomt, is wat Shohaku bewogen heeft tot zijn manier van uitbeelden. De catalogusauteur Kano Hiroyuki doet in de inleiding en de bijschriften wat suggesties, al zegt hij er terecht bij dat het natuurlijk giswerk blijft om de gedachten van de kunstenaar te proberen te achterhalen. In ieder geval is bekend dat Shohaku uit een welvarende familie in Kyoto kwam, net als zijn voorganger in de tentoonstellingsreeks, Jakuchu. Waar de financieel onafhankelijke Jakuchu een lange en onbezorgde schildercarrière was toebedeeld, was het lot Shohaku minder gunstig gezind. Op 17-jarige leeftijd waren zijn broer en beide ouders al overleden. Hij vertrok als jonge man uit Kyoto, om er pas op 46-jarige leeftijd terug te keren. Lange tijd heeft men zelfs gedacht dat hij buiten Kyoto geboren was - deze catalogus helpt bij het rechtzetten van de geschiedenis.

Shohaku was een schilder die zich bewust heeft afgezet tegen zijn tijd en de grote populariteit van de makkelijk toegankelijke werken van Okyo en de zijnen. Hij deed dat door terug te grijpen naar de inktschilderkunst van de 15e-eeuwse Soga Jasoku (gest. 1483) en signeerde dan ook als eerbetoon met 'Soga Shohaku'. Aldus zich afficherend als een schilder uit een lange traditie, legde hij zich net als zijn geadopteerde voorouder toe op het vervolmaken van een energieke penseelvoering, $z i j$ het met een geheel eigen inslag. Soms is die ruig en grillig, soms ingetogen, zoals in het landschap op afbeelding 3. Shohaku zette het imaginaire Chinese berglandschap met veel gevoel voor ritmiek neer in krachtige, zelfverzekerende streken. De lange verticale lijn van de neerstortende waterval wordt aan weerszijden geflankeerd door schuin gehouwen rotsmassa's en ook de brug en het snelstromende water onderin is een spel van diagonalen. Met een groot aantal tinten van lichte en donkere

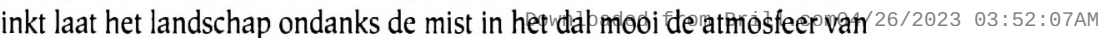



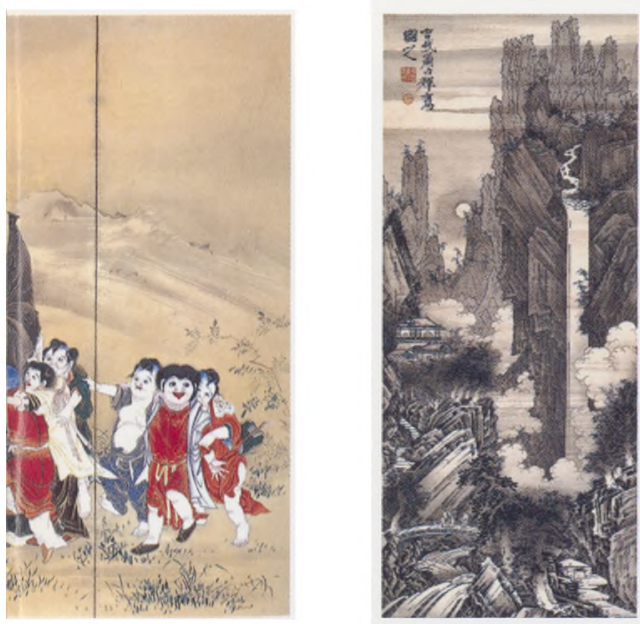

Afbeelding 3

De Drie Lachers in het

Tijgerravijn, hangrol-

schildering, inkt op

papier, Japan, 1760 -

1780, Chiba City

Museum of Art

een volle maannacht zien. In de catalogus wordt geopperd dat Shohaku zich bij het schilderen van dit soort landschappen mogelijk heeft laten inspireren door de natuur tijdens zijn lange verblijf in de provincie.

Het werk van Shohaku is in de 400 pagina dikke catalogus ingedeeld in landschappen, ema (votiefplanken), vogels, dieren en bloemen, en figuren. Aan het eind van het boek volgen nog beschrijvingen van de 122 werken, alle signaturen en zegels apart afgebeeld en een chronologie. Al met al krijgt de lezer een goede indruk van het leven en werk van Shohaku, zij het dat alleen de fotobijschriften en kleine inleidende teksten in het Engels zijn, de substantiële eerste inleiding is in het Japans. Dat hoeft niet direct een bezwaar te zijn, want ook zonder die inleiding is er volop te genieten. De kwaliteit van de illustraties is erg goed en er is bovendien ruim gebruik gemaakt van opgeblazen details en uitvouwbladen: 13 stuks maar liefst, een enkel zelfs verticaal, om een lange schildering helemaal op formaat te kunnen afbeelden. Het is een lust voor het oog en een plezier om te grasduinen door de excentrieke wereld van de Japanse schilder. Ik heb er menige treinreis mee zoet gebracht en kreeg meer en meer spijt dat ik de tentoonstelling in Kyoto op een week na gemist heb. Hopelijk komen er nog herkansingen als de volgende $18 \mathrm{e}$-eeuwse schilders aan de beurt zijn voor een tentoonstelling in het Kyoto National Museum. Wat mij betreft krijgen boek en catalogus drie sterren: il vaut le voyage.

\section{Shohaku Show}

Tentoonstellingscatalogus Kyoto National Museum 12-4/15-5-2005

Kyoto, 2005. 404 pp., ills., $¥ 2500$ (in Nederland rond 45 euro)

\section{Noten}

1. Dialect van de Kansai-streek, letterlijk 'hoe duur is het?'.

2. Ga wo nozomaba waga ni kofubeshi. Ezu wo motomen to naraba Maruyama mondo yokarubeshi. 